\title{
El Secretariado en los Municipios menores de 500 habitantes
}

El art. 233 del Estatuto municipal, de 1924, determinaba que habría dos categorias en el Cuerpo de Secretarios de Ayuntamiento (hasta el Reglamento de funcionarios provinciales, de 2 de noviembre de 1925, no se fusionaron con los Secretarios. de Diputaciones), la primera formada por los Secretarios de poblaciones mayores de 4.000 habitantes o que, sin alcanzar tal cifra, fuesen cabeza de partido judicial, y la segunda consti'tuída por los restantes Municipios.

La escala de sueldos que estableció el art. 37 del Reglamento de Secretarios, Interventores y funcionarios municipales en general, de 23 de agosto de 1924 , era de 2.000 a 4.000 pesetas. para las plazas de. segunda categoría y de $\mathbf{5 . 0 0 0}$ a $\mathbf{1 5 . 0 0 0}$ pesetas para las de primera.

La Ley municipal de $\dot{31}$ de octubre de 1935 , determinó, en su art. 171, que los Secretarios de Administración Local (refundidos ya los de Ayuntamientos y Diputaciones, se adoptó este término más genérico), estarian divididos en trés categorías; la primera, constituída por los Secretarios de Ayuntamientos de capitales de provincias (fuere cual fuere su censo), poblaciones de más de 8.000 habitantes (se elevó así hasta esta cifra el anterior tope de 4.000 habitantes) y los de Diputaciones provinciales; la segunda, compuesta por los Municipios de 2.000 a 8.000 habitantes, y la tercera, integrada por los. de más de $\mathbf{5 0 0}$ habitantes a $\mathbf{2 . 0 0 0}$. 
Estas tres categorías integran, a partir de la fecha de tal Ley, el Cuerpo Nacional de Secretarios de Administración Local.

¿Cuál es la situación, en'tonces, de los Secretarios de Municipios inferiores a $\mathbf{5 0 0}$ habitantes?

En primer lugar, por exclusión del art. 171, citado, no forman parte del Cuerpo Nacional. Además, el último párrafo de dicho artículo dice lo siguiente:

"Se crea una clase especial de Secretarios para Municipios inferiores a $\mathbf{5 0 0}$ habitantes. Tales funcionarios se considerarán como Secretarios Habilitados y no figurarán en el Escalafón general del Cuerpo. Podrán ser nombrados libremente por los Ayuntamientos, siempre que ostenten el oportuno Titulo obtenido en virtud de examen ante Tribunal competente».

Creada, como se ve, tal Clase de Secretarios de Ayuntamiento, por la Ley municipal de 1935, la libre designación por los Ayuntamientos está limitada por la condición exigible d: hallarse en posesión del oportuno Título obtenido "en virtud de examen ante Tribunal competenten.

¿Quién habría de expedir tal Título? La Ley no lo dice. pero la interpretación más exacta parece ser, a nuestro juicio, la de que tales títulos han de ser conferidos por un solo Tribunal, eligiendo después los Ayuntamientos entre las personas así tituladas.

La existencia de una sola jurisdicción para la expedición de aquellos títulos no excluiría la descentralización de tal Tribunal, que podría desdoblarse o trasladarse a las capitales de provincia, en beneficio de la modestia del aspirantado.

Nada de esto se ha hecho al cabo de trece años de vigencia de la Ley municipal de 1935, sino que, por el contrario, se mantiene en unos 3.000 Municipios, que es aproximadamente el número de los menores de $\mathbf{5 0 0}$ habitantes, una situación de anormalidad absoluta en relación con sus Secretarías, que se encuentran servidas de una forma confusa, por personal que no acierta a saber si su situación es propietaria o interina.

Claro que un número de tales Secretarias, cuyo volumen 
ignoramos, continúa servido en propiedad por Secretarios a los que fueron adjudicadas dichas plazas bajo el imperio del Estatuto municipal, como comprendidos entonces en la segun da categoría, última existente. No obstante el tiempo transcurrido, con su secuela de fallecimientos, renuncias, destituciones, traslados y jubilaciones, hace suponer que la mayoría de los pueblos menores de $\mathbf{5 0 0}$ habitantes tienen su Secretaría vacante.

¿Cuál ha sido, realmente, la consecuencia de la creación (no consumada) de la Clase de Secretarios Habilitados por ia Ley de 1935 ? Pues que a partir de la promulgación de tal Ley, la Dirección General de Administración Local, en cumplimiento. de la legalidad vigente, ha venido ajustando las oposiciones convocadas para ingreso en cualquiera de las Categorías del Cuerpo Nacional de Secretarios, a las tres Categorías prescritas y convocando los concursos correspondientes, para la adjudicación de plazas, con la obligada exclusión de los Municipios inferiores a $\mathbf{5 0 0}$ habitantes.

Estos Municipios, cuya Secretaría ya estuviese vacante al aparecer la Ley de 1935, o que hubiere vacado, por cuミlquier motivo, desde entonces, se encuentran, a partir del respectivo momento, sin un Secretario oficialmene capacitado (las excepciones, de hecho, de Secretarios interinos competentes, no niegan la afirmación), es decir, a la deriva, faltos del control técnico que en esos Municipios pequeños constituye el Secretario, casi exclusivamente.

$\mathrm{Ni}$ el Estado provee tales Secretarías, por la razón indicada, ni se prepara a ninguna persona, confiriéndole el Título enunciado al efecto, para el desempeño de las Secretarías Habilitadas. En consecuencia, como los Ayuntamientos no cuentan con el personal titulado que determina el art. 171 de la Ley municipal de 1935, vigente, viénense, por imperio de la realidad, haciendo una serie de nombramientos de Secretarios, bajo la más anárquica expresión de apelativos (propietarios, interinos, accidentales, habilitados) ninguno de los cuales da al funcionario 
y a la propia Corporación la conciencia exacta de su verdadera situación (1).

Hacemos especial hincapié en ia gravisima significación que. tiene el hecho de que muchos contenares de Municipios españoles, por la carcncia de un Secretario con la formación profesional adccuada, se encucntren en tal abandono técnico, agravado por la carencia en tales Municipios de otros funcionarios calificados, y, en multitud de casos, al contrario que en las poblaciones de más importancia, de alguno con cierta preparación municipalista.

Es algo más tranquilizador el panorama que ofrece el Proyecto de Ley articulada de Régimen Local, si llegara a ser una realidad en el "Boletín Oficial del Estado" (2).

La Base 55 de la Ley de Bases de Régimen Local, de 17 de. julio de 1945, dispone que subsistirán las actuales categorías en. el Cuerpo de Secretarios de Administración Local.

Esta expresión amplia se ha interpretado en el Proyecto articulado, pendiente de aprobación del Gobierno, en el sentido de considerar incluídos en la tercera categoría "los pueblos inferiores a 2.001 habitantes", sin más subdivisiones.

¿Es que desaparecen, por tanto, los Secretarios Habilitados de la Ley de 1935, non natos realmente? El referido Proyecto de Ley preceptúa una fórmula más ajustada a la realidad de los pequeños Municipios:

"No obstante - dice el párrafo 3 del art. $36 \mathrm{~S}$ del Proyecio

(1) Las situaciones personales que tienen creadas estos desvaidos funcionarios son verdaderamente tristes. En primer. lugar habria que dilucidar si rigen para ellos las mismas normas reglamentarias que para los Secretarios de Administración Local que constituyen el Cuerpo Nacional, o simplemente las que se aplican a los funcionarios administrativos de los Ayuntamientos (el Reglamento mínimo de 14 de mayo de 1928), y aun acla:ado esto, pocos beneficios habrian de deducirse de ello, puesto que, hasta hoy, no pueden ser considerados funcionarios en propiedad (aunque se haya utilizado al designarles este término) por carencia de las condiciones. exigidas por el artículo $\mathbf{1 7 1}$ de la Ley de 1935, encontrándose ellos y sus familiares al margen del devengo de Derechos pasivos, entre otras desventajas.

(2) Dicha articulación fué realizada por una Comisión de profesores $\mathrm{v}$ técnicos, en el seno del Instituto de Estudios de Administración Local, presidida por el Ilmo. Sr. Director general de Administración Local, D. José Fernández Hernando, y asistida por mí como Vocal-Secretario. 
de la Comisión del Instituto, indicado- en los Municipics inferiores a $\mathbf{5 0 0}$ habitantes podrá habiiitarse a una persona apta para que desempeñe las funciones de Secretario, sin que en modo alguno el ejercicio de las mismas suponga creaciones de derechos, para formar parte del Cuerpo Nacional, a favor del interesado. Serán nombrados por los Ayuntamientos entre los vecinos que tengan algún Título profesional o sean Clases de los Ejércitos, o posean certificado de aptitud obtenido en virtud de examen ante el Tribunal designado por el Instituto de Estudios de Administración Local o sus Delegaciones. La Corporación vendrá obligada en todo caso a dar cuenta de tales nombramientos, en el plazo máximo de ocho días, 'a la Dirección General de Administración Local».

Es decir, interpretamos nosotros, que si el referido Proyecto de Ley de Régimen Local llegara a ser una realidad legal, la Dirección General de Administración Local, al convocar los concursos de provisión de Secretarios de Ayuntamientos de tercera categoría, comprendería en los mismos todos los inferiores a 2.001 habitantes. Si se diera el caso previsible, por la poca importancia de las plazas, de que no fueran solicitadas o provistas, en mayor o menor número, Secretarías de Municipios inferiores a $\mathbf{5 0 0}$ habitantes, podrán las Corporaciones designar un Secretario Habilitado, en los términos indicados en e! artículo del Proyecto de Ley que hemos transcrito.

No cabe duda de que, así, el mal señalado se aminorará, pues muchas plazas serían seguramente adjudicadas a Secretarios de los que hoy constituyen la tercera categoría, pero podría subsistir, en cuanto a las restantes, si se dejara incumplida, como en el año 1935, la preparación de un plantel de Secretarios Habilitados y no se aclararan sus derechos.

Como esto constituye un supuesto, dado que se trata sólo de un proyecto, hemos de atenernos a la realidad presente, que es la que señalamos anteriormente. Partiendo de ta! realidad, estimamos que la situación podría remediarse de esta forma :

1. ${ }^{\circ}$ Formulando el Escalafón de Secretarios Habilitados en el ejercicio de sus plazas, en momento determinado. 
2..$^{\circ}$ Considerando en propiedad a los mismos, mediante la práctica de un breve Cursillo de perfeccionamiento en las capitales de provincia que resultase oportuno (1).

3..$^{\circ}$ Organizando las enseñanzas, para el ingreso en el futuro, en tales plazas de Secretarios Habilitados, dándose así cumplimiento al art. 171 de la Ley municipal de 31 de octubre de 1935.

4. Incluyendo, después de la discriminación prevista en el apartado $1^{\circ}$, a la Clase de Secretarios Habilitados, en e' Montepío General de Secretarios, Interventores y Depositarios de Administración Local.

5..$^{\circ}$ Permitiéndoles asociarse profesionalmente, igualmente que está colegiado el resto del Secretariado, para procurar ia elevación de la Clase que tal colegiación persigue siempre.

\section{Alberto Gallego y Burín}

Secretario general del lastituto de Estudios de Administración Local

(1) Al hablar de esta mateia no concebimos que ya pueda intervenir en Espaت̆ia otro órgano que el Instituto de Estudios de Administración Local. 